\title{
High glucose alters fetal rat islet transcriptome and induces progeny islet dysfunction
}

\author{
Jose Casasnovas ${ }^{1, *}$, Yunhee Jo1,*, Xi Rao², Xiaoling Xuei², Mary E Brown³ and Kok Lim Kua1 \\ 1Department of Pediatrics, Indiana University School of Medicine, Indianapolis, Indiana, USA \\ ${ }^{2}$ Center for Medical Genomics, Department of Medical and Molecular Genetics, Indiana University School of Medicine, Indianapolis, Indiana, USA \\ ${ }^{3}$ The Indiana Center for Biological Microscopy, Division of Nephrology, Indiana University School of Medicine, Indianapolis, Indiana, USA
}

Correspondence should be addressed to K L Kua: kkua@iu.edu

*(J Casasnovas and Y Jo contributed equally to this work)

\begin{abstract}
Offspring of diabetic mothers are susceptible to developing type 2 diabetes due to pancreatic islet dysfunction. However, the initiating molecular pathways leading to offspring pancreatic islet dysfunction are unknown. We hypothesized that maternal hyperglycemia alters offspring pancreatic islet transcriptome and negatively impacts offspring islet function. We employed an infusion model capable of inducing localized hyperglycemia in fetal rats residing in the left uterine horn, thus avoiding other factors involved in programming offspring pancreatic islet health. While maintaining euglycemia in maternal dams and right uterine horn control fetuses, hyperglycemic fetuses in the left uterine horn had higher serum insulin and pancreatic beta cell area. Upon completing infusion from GD20 to 22, RNA sequencing was performed on GD22 islets to identify the hyperglycemia-induced altered gene expression. Ingenuity pathway analysis of the altered transcriptome found that diabetes mellitus and inflammation/cell death pathways were enriched. Interestingly, the downregulated genes modulate more diverse biological processes, which includes responses to stimuli and developmental processes. Next, we performed ex and in vivo studies to evaluate islet cell viability and insulin secretory function in weanling and adult offspring. Pancreatic islets of weanlings exposed to late gestation hyperglycemia had decreased cell viability in basal state and glucose-induced insulin secretion. Lastly, adult offspring exposed to in utero hyperglycemia also exhibited glucose intolerance and insulin secretory dysfunction. Together, our results demonstrate that late gestational hyperglycemia alters the fetal pancreatic islet transcriptome and increases offspring susceptibility to developing pancreatic islet dysfunction.
\end{abstract}

\author{
Key Words \\ - maternal hyperglycemia \\ - fetal hyperglycemia \\ - late gestation \\ hyperglycemia \\ - offspring of diabetic \\ mothers \\ - pancreatic islet \\ programming \\ - fetal islet transcriptome
}

\section{Introduction}

Diabetes complicates $5.6-11.7 \%$ of all pregnancies (Hunt \& Schuller 2007, DeSisto et al. 2014), with affected mothers and offspring vulnerable to adverse metabolic outcomes (Ratner et al. 2008, Fraser \& Lawlor 2014, Tam et al. 2017, Das Gupta et al. 2018). Offspring of diabetic
Journal of Endocrinology (2019) 240, 309-323 mothers suffer a four- to eight-fold increased risk of developing type 2 diabetes (Clausen et al. 2008) due to obesity (Raghavan et al. 2017), insulin resistance (Sauder et al. 2017) and pancreatic islet dysfunction (Gautier et al. 2001, Tam et al. 2017). In addition to increased adiposity, 
recent human studies have shown that by the age of 7 years, children born to diabetic mothers had impaired glucose tolerance and decreased beta cell compensation (Tam et al. 2017). Animal offspring exposed to a diabetic milieu in utero also exhibited pancreatic islet dysfunction (Cerf et al. 2006, Han et al. 2007, Blondeau et al. 2011, Zambrano et al. 2016). While both human and animal studies confirmed that the altered in utero environment during diabetic pregnancy permanently reprograms the metabolic health of offspring, the underlying mechanisms modulating offspring pancreatic islet function remain poorly understood.

During maternal diabetes (type 1, type 2 and gestational diabetes), maternal hyperglycemia occurs secondary to inadequate insulin secretion and/or underlying insulin resistance. Commonly used animal models simulating diabetic pregnancy, such as chemically induced maternal diabetes (insulin deficiency model) (Han et al. 2007, Blondeau et al. 2011) or maternal highfat diet model (maternal insulin resistance/obesity) (Cerf et al. 2006, 2009, Zambrano et al. 2016), expose developing fetuses to a multitude of maternal biochemical changes far beyond hyperglycemia during critical development periods (Xiang et al. 2007, Wang et al. 2010). Maternal hyperglycemia has been implicated as the primary contributing factor (Clausen et al. 2008, Tam et al. 2017, Martin \& Sacks 2018) and has been shown to induce pancreatic islet dysfunction early during fetal life (Frost et al. 2012, Green et al. 2012). However, the exact means by which maternal hyperglycemia impacts offspring metabolic health is unknown due to (1) the absence of a rodent model capable of exposing the developing fetus to an exclusively excessive glucose supply and (2) a limited understanding in early transcriptome changes induced by maternal hyperglycemia.

Both rodents and humans undergo continuous pancreatic beta cell mass expansion and functional maturation postnatally until young adulthood (BonnerWeir et al. 2016). This process of postnatal pancreatic beta cell mass expansion and functional maturation is tightly regulated by transcription factors (e.g. MAFB, UCN3) (Artner et al. 2007, van der Meulen \& Huising 2014), miRNA (Jacovetti et al. 2015, 2017) and growth factors (insulin, INGAP) (Barbosa et al. 2006). Changes in any of these factors could affect the biological and mechanistic pathways involved with diabetes-induced pancreatic islet dysfunction in offspring.

The aim of this study was to identify early transcriptome changes induced by maternal hyperglycemia on pancreatic islets of offspring, uncovering a primary

(C) 2019 Society for Endocrinology Published by Bioscientifica Ltd. Printed in Great Britain mechanism of offspring pancreatic islet programming. We hypothesize that maternal hyperglycemia alters the offspring pancreatic islet transcriptome, consequently conferring increased offspring susceptibility to developing pancreatic islet dysfunction. To create the fetal hyperglycemic environment, we employed a model capable of inducing localized fetal hyperglycemia in rats (Yao et al. 2010, Gordon et al. 2015). While maintaining maternal euglycemia, this model targets glucose delivery to fetuses residing in the left uterine horn, allowing the use of fetuses in the right uterine horn as genetically similar controls as they remain normoglycemic (Yao et al. 2010, Gordon et al. 2015). Using an RNA sequencing approach, we identified early transcriptome alterations induced by late gestation hyperglycemia in fetal islets. Subsequently, we selected regenerating islet-derived protein 3-gamma $(\operatorname{Reg} 3 g)$ for validation due to its highest fold change and reported protective role as compensatory factor during islet stress (Marselli et al. 2010, Xia et al. 2016). Based on the biological processes enriched and functions of differentially expressed genes, we performed additional $e x$ and in vivo studies evaluating weanling and offspring pancreatic islet cell viability and insulin secretory function. Together, our results showed that offspring exposed to late gestational hyperglycemia acutely developed pancreatic islet morphological changes with altered islet transcriptomes that have critical functions on pancreatic islet health, and subsequently developed persistent pancreatic islet dysfunction as early as weaning.

\section{Methods}

\section{Animals}

All procedures conformed to the regulations of the Animal Welfare Act and the National Institutes of Health Guide for the Care and Use of Laboratory Animals and were approved by the Indiana University School of Medicine Institutional Animal Care and Use Committee. Rodents were housed in a temperature controlled, 12-h light-dark cycled animal care facility with free access to water and regular chow.

\section{Localized fetomaternal hyperglycemia}

On gestation day (GD) 20, a vascular catheter draining into the left uterine artery was placed in timed pregnant $C D$ Sprague Dawley rats (Charles River, Wilmington, MA, USA) to infuse glucose directly into the left uterine artery (Yao et al. 2010, Gordon et al. 2015). Maternal tail vein blood 
glucose levels were measured prior to anesthesia ( $n=13$ GD 20 dams). Anesthesia was induced using isoflurane inhalation with oxygen. A 3 Fr Polyurethane Catheter (Norfolk Access, IL, USA) was inserted and secured $1.75 \mathrm{~cm}$ retrograde into the femoral artery, thus placing the tip of the catheter several millimeters proximal to uterine artery divergence from the common iliac artery. The left inferior peritoneal space was explored and superfine microclips (GEM 1521, Synovis Micro Companies Alliance Inc, AL, USA) were placed on the superior gluteal and hypogastric trunk arteries. The catheter was tunneled subcutaneously to exit at the mid-scapular space and connected to a single channel infusion swivel (Instech, PA, USA), allowing rats to move freely. Following this procedure, glucose (D20W) was infused at $4 \mathrm{mg} / \mathrm{min}(20 \mu \mathrm{L} / \mathrm{min})$ until GD22 (term). All pregnant dams received the same postoperative analgesia. Topical bupivacaine was applied immediately after wound closure and subcutaneous buprenorphine SR $(0.5 \mathrm{mg} / \mathrm{kg})$ was given once preoperatively with Meloxicam $(3 \mathrm{mg} / \mathrm{kg}$ ) once daily until delivery. After measuring maternal tail vein glucose level ( $n=13$ GD22 dams), GD 22 pregnant dams were anesthetized for laparotomy. Left and right uterine vein blood was collected prior to fetal extraction for glucose measurement using an Alphatrak Glucometer (Zoetis, NJ, USA) ( $n=15$ GD22 dams). After delivery, pups exposed to hyperglycemic infusion (HG) and respective right uterine horn controls (Con) were either euthanized for sample collection and blood glucose measurement (n 22-26 fetus; 12-14 neonates per group) or resuscitated and cross-fostered to healthy dams who delivered a day apart. Negative control experiment was performed using the same surgical approach but dams were infused with normal saline ( $n=3$ GD20 pregnant dams).

\section{Islet isolation}

Fetal pups were euthanized immediately after delivery and the abdominal surface was sterilized with $70 \%$ ethanol. Laparotomy was performed and the fetal pancreas was separated from surrounding tissue starting from the spleen. One pancreas from each gender was pooled and cut into pieces smaller than $3 \mathrm{~mm}$. Collagenase (Worthington, $1 \mathrm{~mL}$ of $2 \mathrm{mg} / \mathrm{mL}$ concentration per pancreas) was added and the tissue/collagenase mixture was incubated at $37^{\circ} \mathrm{C}$ for 10-12 min with intermittent manual shaking. Subsequently, a $10 \mathrm{~mL}$ syringe attached to $20 \mathrm{G}$ needle was used for aspiration-ejection to homogenize the tissue lysates. Next, HBSS/BSA was added to deactivate collagenase. The lysate was centrifuged, supernatant was removed and the digested pellet was resuspended with RPMI 1640 media. Lastly, islets were handpicked and cultured in RPMI 1640 media with $5.5 \mathrm{mM}$ glucose. For weanlings, islets were isolated per standard ductal inflation technique (Stull et al. 2012).

\section{RNA sequencing}

The mRNA sequencing was performed by the Center for Medical Genomics at the Indiana University School of Medicine. Fetal islets were isolated as described earlier. Three set of paired fetal islet samples collected from fetuses from three independent infusions were used for RNA sequencing. Total islet RNA was extracted using an RNeasy micro kit (Qiagen) following the manufacturer's instructions. Purified total RNA was first evaluated for its quantity and quality using the Agilent Bioanalyzer 2100. A RIN (RNA Integrity Number) of five or higher was required to pass the quality control. 65-150 ng of total RNA per sample were used for library preparation. cDNA library was generated and indexed individually. The cDNA library preparation included mRNA purification/enrichment, RNA fragmentation, cDNA synthesis, ligation of index adaptors and amplification following the TruSeq Stranded mRNA Sample Preparation Guide (RS-122-9004DOC, Part\# 15031047 Rev. E; Illumina, Inc.). Each resulting indexed library was quantified and its quality assessed by Qubit and Agilent Bioanalyzer, and then pooled in equal molarity according to the guide. Average size of library insert was about $150 \mathrm{~b}$. Five microliters of $2 \mathrm{nM}$ pooled libraries per lane were then denatured, neutralized and applied to the cBot for flow cell deposition and cluster amplification, before loading on to HiSeq 4000 for $75 \mathrm{~b}$ paired-end sequencing (Illumina, Inc.). A Phred quality score (Q score) was used to measure the quality of sequencing. More than $90 \%$ of the sequencing reads reached Q30 (99.9\% base call accuracy). Median raw reads were 41 million per sample. The sequencing data were mapped to the rat genome (UCSC rn6) using a STAR RNA-seq aligner (Dobin et al. 2013) and read counts were summarized using featureCounts (subread) (Dobin et al. 2013, Liao et al. 2014) to get gene expression data. Seventy three percent of the reads were mapped to the gene area. The genes with no/low expression were removed and the expression data were normalized using the trimmed mean of $M$ values (TMM) method. Differential expression analysis was performed using edgeR (Robinson et al. 2010, McCarthy et al. 2012), and the false discovery rate (FDR) was computed from $P$ values using the BenjaminiHochberg procedure $(n=3$ paired replicates per group 
from three separate infusions). Sequencing data can be found at GEO (GSE118323).

\section{Ingenuity pathway analysis (IPA) package and GO biological process enrichment}

Differentially expressed genes (FDR $<0.05$ and $\mathrm{FC}>1.5$ ) were analyzed using two pathway analyses. IPA package was used to identify enriched pathways and disease processes (adjusted $P$ value $<0.05$ after Bonferroni correction). Next, the GO biological processes enriched by upregulated and downregulated genes were identified separately using the PANTHER overrepresentation test (database version: GO Ontology database Released 2018-05-21, Reference List: Rattus Norvegicus, Annotation Data Set: GO Biological Process complete, Test Type: Fisher's Exact With FDR multiple test correction, FDR $<0.05$ as significant) (Mi et al. 2017) and visualized using REVIGO (Supek et al. 2011).

\section{Quantitative RT-PCR (RT-qPCR)}

Additional sets of paired fetal islet samples collected as described above were used to validating RNA sequencing findings ( $n=5$ paired replicates from five mothers, of those one was technical replicate from RNA-seq). For RT-qPCR, total RNA was purified and reverse transcribed at $37^{\circ} \mathrm{C}$ with $15 \mu \mathrm{g}$ of random hexamers, $0.5 \mathrm{mM}$ dNTPs, $5 \times$ first strand buffer, $0.01 \mathrm{mM}$ dithiothreitol and $200 \mathrm{U}$ of M-MLV reverse transcriptase (Invitrogen) in a final reaction volume of $20 \mu \mathrm{L}$. RT-qPCR was performed using a SYBR Green-based methodology and primers that were synthesized commercially (Table 1). Briefly, $0.4 \mu \mathrm{L}$ of forward primer $(5 \mu \mathrm{M}), 0.4 \mu \mathrm{L}$ of reverse primer $(5 \mu \mathrm{M}), 5 \mu \mathrm{L}$ of $2 \times$ SYBR Green PCR Master mix (Applied Biosystems, NBY), and $4.2 \mu \mathrm{L}$ of cDNA were mixed. Next, the reactions were amplified for 40 cycles using Applied Biosystems QuantStudio 3 Real-Time PCR system (Applied Biosystems).

\section{Immunohistochemistry/immunofluorescence}

Pancreas was removed from animals after euthanasia and fixed rapidly, embedded in paraffin and sectioned into $5 \mu \mathrm{m}$ thick slices, with one section of each group on the same slide to avoid slide-to-slide variation. Two to three sections per animal were analyzed for all immunohistochemistry/immunofluorescence studies. The pancreatic sections were deparaffinized and rehydrated through a series of graded ethanol solutions. Endogenous peroxidase activity blockade was performed and antigens were retrieved by microwaving slides with unmasking solution (Vector Laboratories). To identify pancreatic endocrine cell areas (fetus: 5-6 pups/group from five mothers; adult offspring: 4 males/group from four mothers), sections were incubated with anti-insulin (Santa Cruz sc-9168, 1:500) or anti-glucagon antibodies (Santa Cruz sc-13091, 1:500) overnight. Digital images depicting whole pancreatic tissue sections were obtained using an Axio-Scan Z1 inverted microscope (Zeiss). The area of insulin- or glucagon-positive cells (calculated using Zen Pro) was divided by the total area of whole pancreatic sections to obtain the beta- or alpha-cell crosssectional area as a percentage of total pancreatic area. For adult offspring, beta cell mass is calculated by multiplying percent insulin-positive area with total pancreatic mass. To assess relative REG3G distribution in beta-cells (GD22 fetus: 5 pups/group from five mothers), we quantified the ratio of Reg3g-stained volume to that of insulin. Pancreatic sections were incubated with anti-insulin antibody (Santa Cruz sc-9168, 1:500) and anti-REG3G antibody (Antibodies Online, ABIN3023039, 1:200) overnight. Pancreatic histological samples were scanned bidirectionally with a Leica TCS SP8 laser-scanning confocal microscope system equipped with a $405 \mathrm{~nm}$ diode laser and $488 \mathrm{~nm}$ and $552 \mathrm{~nm}$ semiconductor lasers and an HC PL APO CS2 $40 \times / 1.30$ oil objective lens through a $68.06 \mu \mathrm{m}$ pinhole (1.0 Airy unit). Emission bandwidths were set to $415-480 \mathrm{~nm}$ for blue emission, $495-545 \mathrm{~nm}$ for green emission and $560-700 \mathrm{~nm}$ for red emission. Twelvebit $1024 \times 1024$ voxel images were collected at a voxel volume of $0.212 \mu \mathrm{m} \times 0.212 \mu \mathrm{m} \times 0.502 \mu \mathrm{m}$ with a line average setting of two using LAS X v3.1.5.16308 software. These settings were applied to all acquired images. All image processing was performed with Fiji, version 1.51 (Schindelin et al. 2012). First, Reg3g and insulin images were thresholded with the Li algorithm in Fiji and a region of interest (ROI) was drawn around insulinstained cells. All signal outside the ROI was removed and the insulin signal volume $\left(\mu \mathrm{m}^{3}\right)$ contained within the ROI was quantified with the 3D object counting function in Fiji. This ROI outline was transferred to the corresponding REG3G image and all outside signal was removed. Subsequently, the signal volume $\left(\mu \mathrm{m}^{3}\right)$ within the insulin-defined ROI that was stained positively for REG3G was measured. Finally, the relative expression of Reg3g in beta-cells was determined by calculating the ratio of Reg3g signal volume to insulin volume. 
Table 1 Primer sequences of target genes.

\begin{tabular}{llll}
\hline Gene (accession number) & sequence $\left(5^{\prime}-3^{\prime}\right)$ & company \\
Reg3g (NM_173097.1) & Fwd TGTGCCCACTTCACGTATCA & IDT \\
Reg3b (NM_053289.1) & Rev GGATCATGGAGCCCAATCCA & Sigma \\
Gabrp (NM_031029.1) & Fwd GGAAACAGCTACCAATATACC & Sigma \\
Mmp7 (NM_012864.2) & Rev CTCCATCTTAGAAATCCAGAAG & IDT \\
Actb (NM_031144.3) & Fwd AGATGGCAGTCAAAGATAGG & Eurofins \\
& Fwd ACAGACTTGCCTCGGTTCTT & Rev GTCTCCGTGATCTCCCCTTG \\
\hline
\end{tabular}

\section{Ex vivo islet glucose-stimulated insulin secretion (GSIS)}

Isolated islets from weanlings ( $n=5$ male weanlings/group from five mothers) were recovered in RPMI overnight prior to measuring insulin secretion under static glucose incubation (Komatsu et al. 1995, Mehta et al. 2016). 20-25 size-matched weanling islets were incubated in Krebs-Ringer bicarbonate buffer $(129 \mathrm{mM} \mathrm{NaCl}$, $5 \mathrm{mM} \mathrm{NaHCO}_{3}, 4.8 \mathrm{mM} \mathrm{KCl}, 1.2 \mathrm{mM} \mathrm{KH} \mathrm{PO}_{4}, 2.5 \mathrm{mM}$ $\mathrm{CaCl}_{2}, 1.2 \mathrm{mM} \mathrm{MgSO}_{4}, 0.1 \%$ BSA, $10 \mathrm{mM}$ Hepes, $\mathrm{pH}$ 7.4) containing $2.8 \mathrm{mM}$ glucose for $1 \mathrm{~h}$ at $37^{\circ} \mathrm{C}$ (pre-incubation). Next, the incubation medium was removed by aspiration and $1 \mathrm{~mL}$ of fresh KRB buffer containing different concentrations of glucose was added $(5.5 \mathrm{mM}$ and $16.7 \mathrm{mM})$ to determine islet insulin secretory function at different glucose levels. At the end of incubations, the medium was aspirated and stored at $-80^{\circ} \mathrm{C}$ until measurement. At the end of the static culture, total insulin of pancreatic islets was extracted using acid-ethanol extraction $(1.5 \% \mathrm{HCl}$, $75 \% \mathrm{EtOH}, 0.1 \%$ Triton). Weanling ex vivo islet GSIS media insulin concentration was measured using Stellux Chemi Rodent Insulin ELISA (ALPCO, NH, USA). Results were analyzed and presented as a percentage of total insulin.

\section{In vivo metabolic evaluations of offspring}

Metabolic phenotypes of weanlings and adult offspring were evaluated using intraperitoneal glucose tolerance testing (GTT) (weanling: total 14-19 males/group from nine mothers; 2-month-old adult: 6-7 males/group from five mothers) and intraperitoneal insulin tolerance testing (ITT) ( $n=4-6$ male weanlings/group from three mothers). Animals were fasted for $6 \mathrm{~h}$ prior to both tests. For GTT, 1 or $2 \mathrm{~g} / \mathrm{kg}$ of glucose was injected intraperitoneally and blood was collected from animals via tail vein at $0,10,20,30,60,90$ and 120-min time points. Additional blood was collected at 10 and $30 \mathrm{~min}$ from adult offspring for serum insulin measurement. For ITT, $0.75 \mathrm{U} / \mathrm{kg}$ of Humulin R (Eli Lilly) was administered and blood glucose was measured at 0,15 , 30, 45 and 60-min time points. Animal blood glucose levels were measured with an Alphatrak Glucometer (Zoetis, NJ, USA). Fetal serum insulin concentrations were measured using the Ultrasensitive Rat Insulin ELISA kit (\#90060, Crystal Chem, Downers Grove, IL, USA). Adult serum insulin levels were measured using Stellux Chemi Rodent Insulin ELISA (ALPCO).

\section{Alamar blue cell viability assay}

Isolated islets from weanlings ( $n=4$ pups/group from four mothers) were recovered in RPMI 1640 media containing $11 \mathrm{mM}$ glucose for $24 \mathrm{~h}$ prior to evaluation. Seven to eight size-matched islets were handpicked into 96 wells with $100 \mu \mathrm{L}$ of regular RPMI media. Sterile Alamar blue was subsequently added in 1:10 dilution and then read hourly with a FlexStation 3 Multi-Mode microplate reader (Molecular Devices, San Jose, CA, USA) at an excitation wavelength of $535 \mathrm{~nm}$ and emission wavelength of $585 \mathrm{~nm}$. Between reads, islets were incubated in a humidified, warm tissue culture chamber. The fluorescence value produced by Con/HG wells was obtained by subtracting the relative fluorescence unit (RFU) of the negative control well (media and Alamar blue, no islets) from the measured RFU in each well at different timepoints.

\section{Statistics}

Each group of fetuses and male offspring originating from one biological mother was considered as $n=1$. In instances where more than one pups from the same mother were analyzed, the average of the acquired data would then 
be used as a single data (Vieleisis \& Oh 1983, Roest et al. 2004, Gordon et al. 2015). All results were represented as mean \pm s.E.M., while fold changes of RT-qPCR results were represented as $\log 2 \mathrm{FC}$ in comparison to RNA-seq results. For single timepoint measurement, the difference between two groups was assessed using a paired twotailed $t$-test. For repeated measures (glucose level during GTT, ITT, GSIS, Alamar blue cell viability assay), two-way ANOVA tests followed by Bonferroni multiple comparison tests correction were performed to assess the difference between two groups. Results were defined as statistically different when $P<0.05$.

\section{Results}

\section{Localized fetomaternal hyperglycemia induces fetal pancreatic islet perturbations}

The localized fetomaternal hyperglycemia model allows for dosage and temporal control over glucose delivery to left uterine horn fetuses (Fig. 1A). To determine the effects of late gestation hyperglycemia, glucose was infused from GD20 to GD22, with offspring evaluated at different timepoints (Fig. 1B). On GD22, maternal blood glucose concentrations were unchanged with ongoing $4 \mathrm{mg} / \mathrm{min}$ glucose infusion (Fig. 1C). To validate the specific targeting of glucose delivery, we measured both the maternal uterine vein and fetal blood glucose level. Indeed, blood glucose concentrations from the maternal left uterine vein were higher than those from the right (Fig. 1C). Compared to internal control fetuses from the right uterine horn (Con), left uterine horn fetal rats (HG) also had higher blood glucose levels (Fig. 1D). As with previously published report (Gain et al. 1981), blood glucose levels of control pups were higher $30 \mathrm{~min}$ after birth (Fig. 1D). In contrast, this increase in glucose level was not apparent in HG pups (Fig. 1D). In fact, when compared to control, newborn pups that received glucose infusion had lower blood glucose levels (Fig. 1D). Not surprisingly, left uterine pups exposed to glucose infusion also had higher serum insulin levels (Fig. 1E) and beta cell areas (Fig. 1F). The higher number of cells within insulinpositive area in hyperglycemic pups (Supplementary Fig. 1, see section on supplementary data given at the end of this article) indicating that the increase in beta cell area likely resulted from cellular hyperplasia. Taken together, fetal pups exposed to transient (48h) hyperglycemia developed both hyperinsulinemia and pancreatic beta cell hyperplasia.
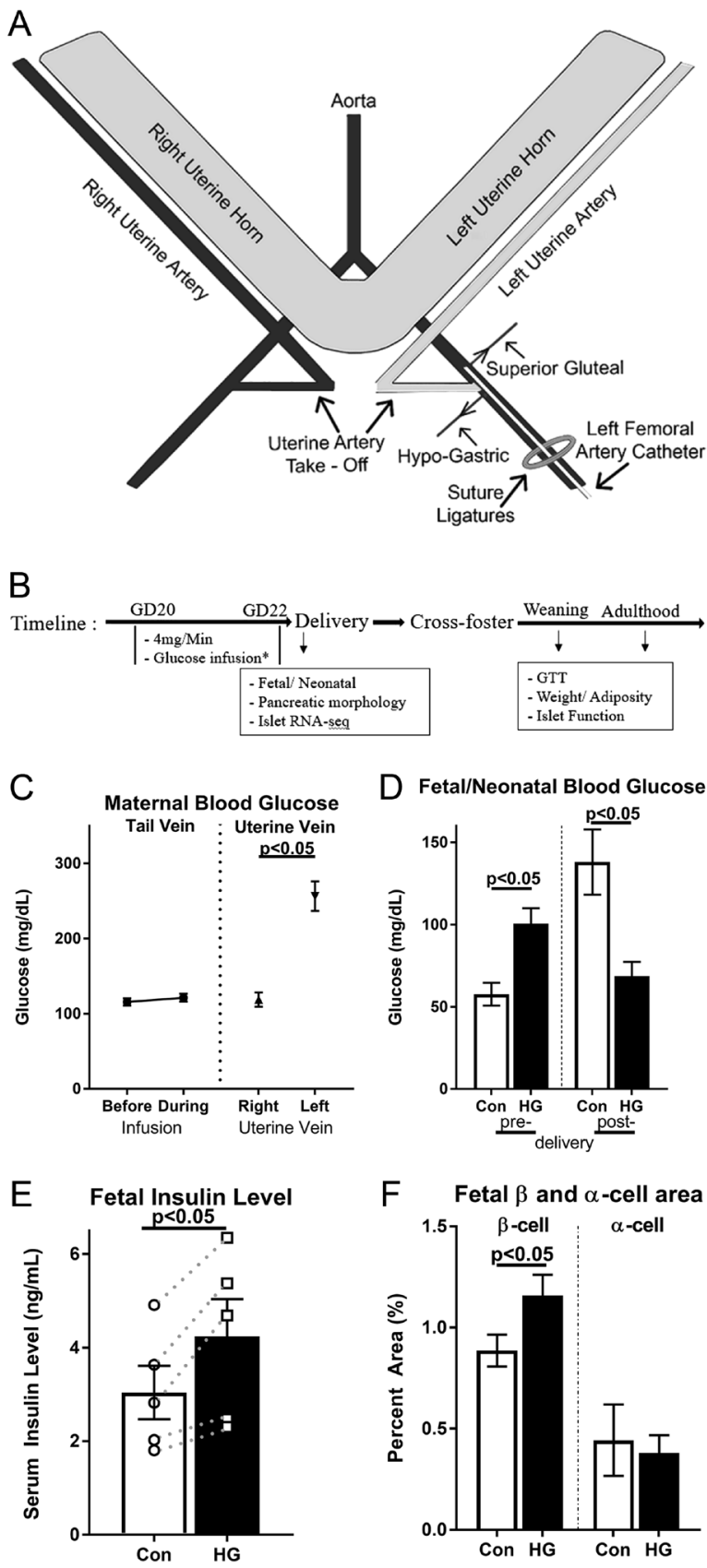

\section{Figure 1}

(A) Schematic representing localized fetomaternal hyperglycemia model. (B) Experimental timeline. Fetal pups were exposed to hyperglycemia from GD20 to 22, delivered via Cesarean section and cross-fostered to healthy dams. The cross-fostered pups were evaluated at weaning and at adulthood. (C) Maternal blood glucose was unchanged before (GD20) and during infusion (GD22) (left panel, $n=13$ mothers). During infusion, the glucose level in blood returning from the left uterine vein was higher than that of the right uterine vein (right panel, $n=15$ mothers). (D) The glucose levels of fetuses residing in left uterine horn $(\mathrm{HG})$ were higher than those of their respective controls (Con) during glucose infusion while the placenta was intact ( $n=22-26$ fetus from 12 mothers), but lower 30 min after birth (right panel, 12-14 pups from seven mothers). (E) Insulin levels of HG pups were higher as well ( $n=5$ pups/group from five mothers). (F) Pancreatic beta- and alpha-cell area in the HG fetal pups ( $n=5-6$ pups/group from five mothers). 
RNA-seq identified differentially expressed genes known to mediate inflammation and pancreatic islet function

To identify the earliest pathway and biological processes altered by hyperglycemia exposure, we performed RNA sequencing to examine whole islets transcriptome changes in GD22 fetal islets immediately after completing $48 \mathrm{~h}$ of glucose infusion. Compared to controls, HG fetal islets had 87 differentially expressed genes (DEGs) (69 up- and 18 down-regulated) (Supplementary Table 1). The result of Ingenuity Pathway Analysis revealed 22 enriched pathways, the majority of which were related to inflammation (Supplementary Table 2). IPA also identified diabetes mellitus as a relevant disease process (24 DEGs) and also predicted the activation of cell death (41 DEGs) (Fig. 2A). Next, the biological processes enriched by up and downregulated genes were identified using the PANTHER classification system (Mi et al. 2017) and visualized using REVIGO (Supek et al. 2011). As shown in the semantic similarity-based scatterplots, the up- and down-regulated genes were involved in different biological processes (Fig. 2B). While the upregulated DEGs were heavily enriched in inflammatory and immune system-related biological processes, the downregulated genes were involved in more diverse biological processes (Fig. 2B). In addition to inflammation, the downregulated genes were also enriched in processes involving cellular responses to stimuli and developmental processes (table in Fig. 2B). To further understand the specific biological implications of these broad terms, we performed a literature review and identified a significant number of down-regulated genes (Ctgf, Clu, Cftr, Fgfr3, Gabrp, Mmp7, Reg3b, Reg3g) that are involved in early pancreatic islet development (proliferation, new islet formation) (Crawford et al. 2009, Koivula et al. 2016), adult pancreatic islet function, neogenesis and antiapoptotic effects during stress (Table 2). Further RT-qPCR validation confirmed both Reg3g and Reg3b, along with two additional downregulated genes (Gabrp and Mmp7), were consistently decreased in GD22 islets exposed to in utero hyperglycemia (Fig. 3A). Furthermore, HG pups revealed a decrease in the percentage of area positive for REG3G staining within insulin-positive cells (Fig. 3B), indicating that $\mathrm{HG}$ beta-cells had diminished REG3G protein expression. Collectively, RNA sequencing results revealed that fetal hyperglycemia induces the islet transcriptome associated with diabetes mellitus and activated islet inflammation/cell death pathways. Interestingly, the downregulated genes are involved in various biological processes that modulate pancreatic islet health.

\section{Pancreatic islet dysfunction occurs in weanlings exposed to hyperglycemia in utero}

Given that late gestational hyperglycemia rapidly alters fetal pancreatic islet phenotypes and transcriptome, it was thus of interest to determine whether offspring were vulnerable to developing pancreatic islet dysfunction. Particularly, we aimed to determine if late gestation hyperglycemia exposure altered offspring pancreatic islet viability and function as predicted by transcriptome analysis. At weaning (P21), HG pups developed impaired glucose tolerance as evidenced by higher glucose levels at 10 min during IPGTT and higher incremental AUC (iAUC) (Fig. 4A, B, C and D). Using the same surgical approach, we performed a separate negative control experiment by infusing normal saline to left uterine horn fetal pups. We observed no difference in IPGTT of saline-infused offspring from the left uterine horn when compared to their internal controls from the right uterine horn (Supplementary Fig. 2). Next, we evaluated weanling pancreatic islet cell viability using the Alamar blue cell viability assay (Muthyala et al. 2017) and insulin secretory function via ex vivo static GSIS. Under basal conditions, pancreatic islets extracted from HG weanlings had lower cell viability suggesting an increased susceptibility to cell death (Fig. 4E). Additionally, HG weanling islets had decreased insulin secretion at both $5.6 \mathrm{mM}$ and $16.7 \mathrm{mM}$ stimulatory phases (Fig. 4F). In the absence of overt insulin resistance during insulin tolerance testing (Fig. 4I), these findings assert that offspring exposed to late gestation hyperglycemia developed glucose intolerance secondary to pancreatic islet dysfunction as observed by decreased cell viability and static glucose-stimulated insulin release.

\section{Adult offspring exposed to HG had decreased beta cell mass and insulin secretory dysfunction without altered growth or increased inflammatory mediators}

We sought to determine if pancreatic islet changes at weaning would impact adult offspring. As beta cell mass and function increase drastically after weaning (Bonner-Weir et al. 2016), we hypothesized that increased susceptibility to cell death and decreased glucose responsiveness in weanling islets would impact both pancreatic beta cell mass and insulin secretory function in HG adults. Indeed, HG adult offspring remained glucose intolerant with an increased glucose tolerance curve divergence (Fig. 5A and B). 
A

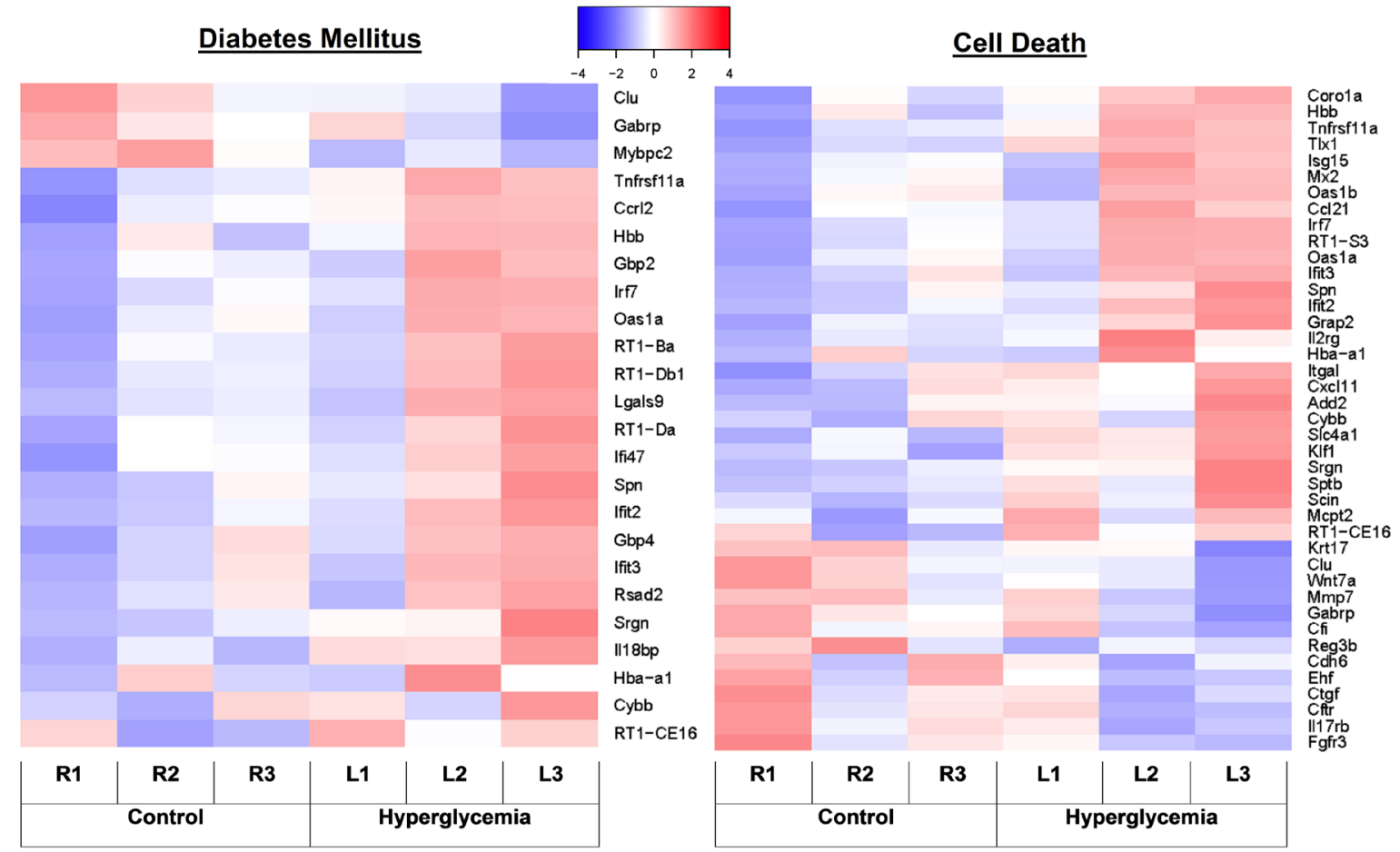

B

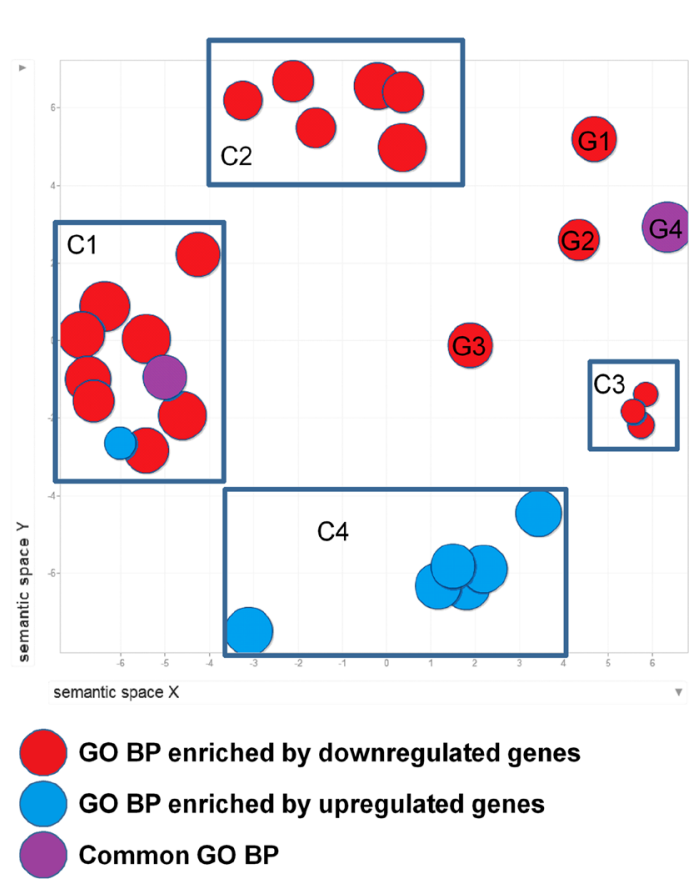

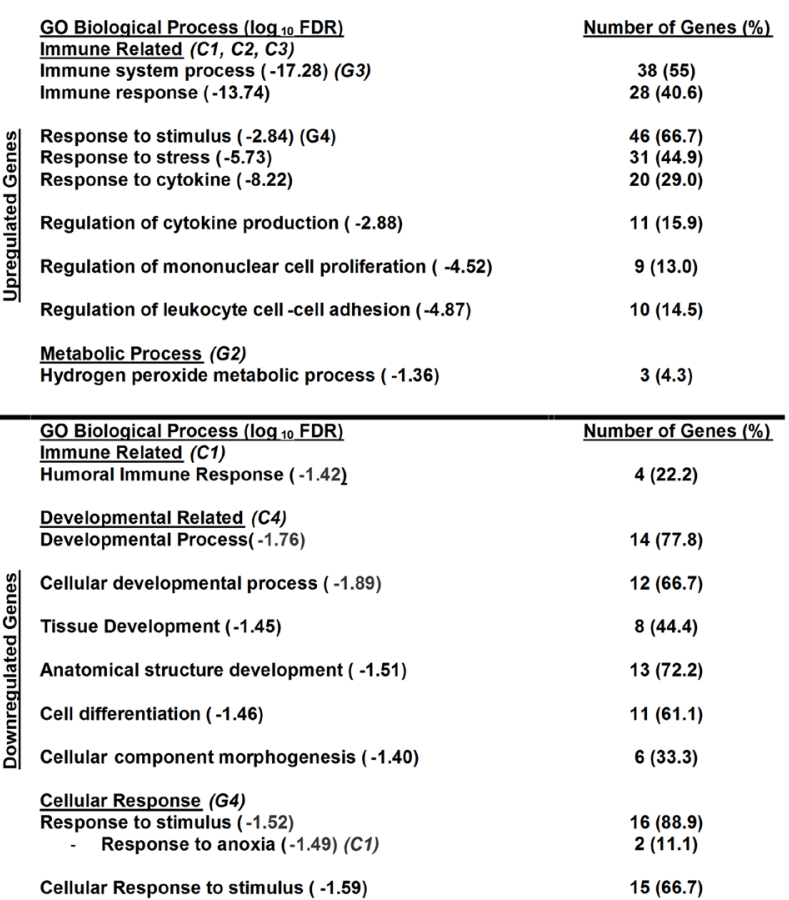

Figure 2

(A) Heatmap showing differentially expressed genes regulating diseases and biofunction predicted by IPA ( $n=3$ fetal islet samples/group from three mothers; each islet samples prepared from pool of one pancreas from each gender). Left panel: 24 genes that enriched diabetes mellitus disease process (adjusted $P$-value $=2.43 \times 10^{6}$ ). Right panel: Cell death process was upregulated by 41 genes (adjusted $P$-value $\left.=2.38 \times 10^{4}\right)$. (B) Upregulated and downregulated DEGs were analyzed separately using PANTHER and enriched GO BP was further summarized using REVIGO with the following parameters - database: whole UniProt; semantic similarity measure: Resnik; similarity allowed: Small (0.5). Note that upregulated genes enriched immune and inflammatory processes (red circles) and downregulated genes enriched different biological processes (blue circles). There were two commonly enriched GO BP (G4 - response to stimulus, purple circle in C1 - immune responses/humoral immune response). The table on right shows the summarized list of GO biological processes (BP) and number/percentage of genes annotated to the GO BP. 

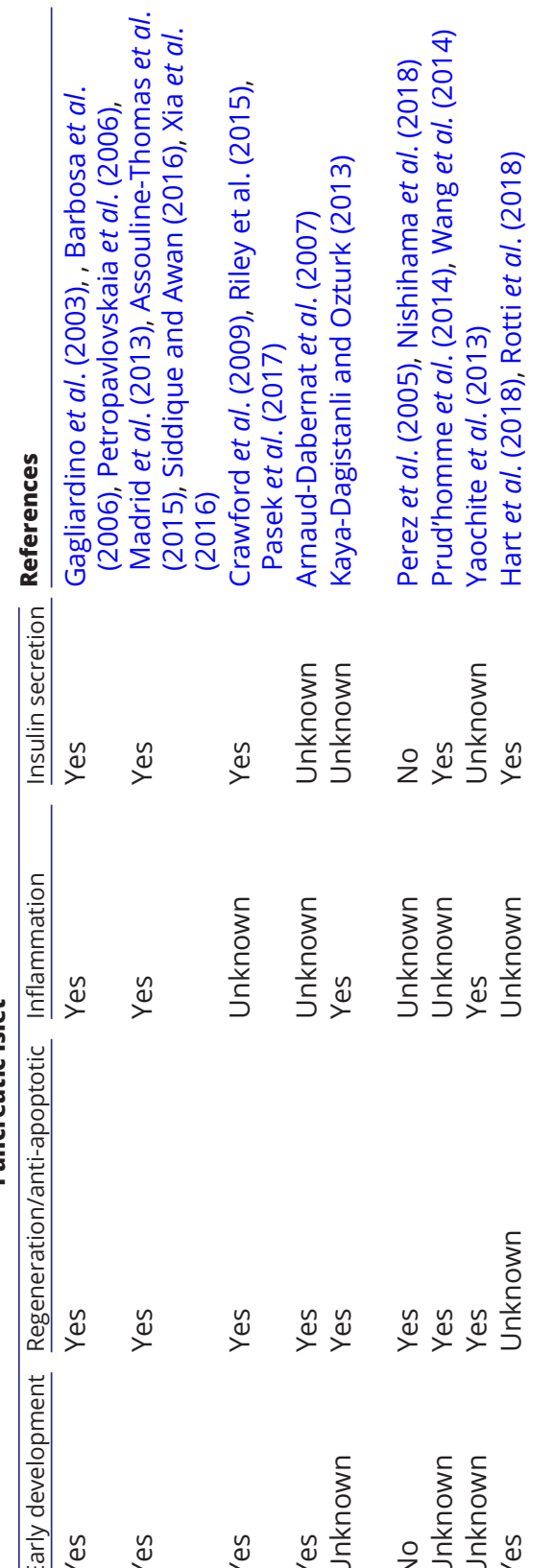

$\stackrel{y}{\nu}$

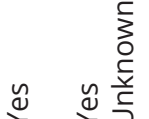

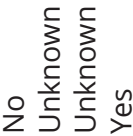

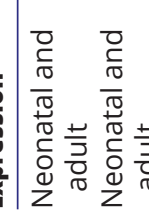

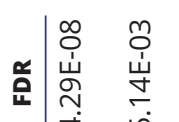

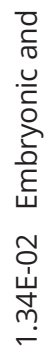

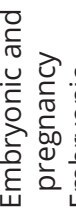

フ̃. ㄲำ

崩 岁岁.

$u \mid \underset{\sim}{\stackrel{m}{*}} \stackrel{i}{i}$

$\stackrel{\infty}{\rightarrow} \stackrel{\circ}{i} \stackrel{0}{i}$

$\stackrel{1}{i} \stackrel{1}{\sim}$

$\dot{1} \dot{0} 0$

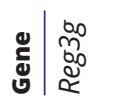

के
बें

㤎
Despite a higher serum glucose level, HG adults had diminished in vivo insulin release $10 \mathrm{~min}$ after glucose injection (Fig. 5C). Additionally, HG adults also had lower pancreatic beta cell mass (Fig. 5D, E and F). To determine if altered growth or increased adiposity contributed to glucose intolerance, we measured offspring weight and adiposity at weaning and at 2 months. There were no differences between offspring who received in utero hyperglycemic infusion and their respective controls (Fig. 5G and H). Since the inflammatory pathways were overrepresented, we also measured five inflammasomes in fetal, neonatal and 2-month-old offspring, in which three were IPA predicted (IFNG, TNF-alpha, IL1B) and two were associated with the upregulated DEGs (CXCL10, IL-17). However, the levels of these inflammatory mediators in the serum both during early life and at 2 months were unchanged (Supplementary Fig. 3). These findings indicated that pancreatic islet dysfunction was not mediated by altered growth, increased adiposity or systemic inflammation.

\section{Discussion}

Independent of genetic risk, offspring born from diabetic pregnancies experience a greater risk of insulin resistance, pancreatic islet dysfunction and type 2 diabetes (Ratner et al. 2008, Fraser \& Lawlor 2014, Tam et al. 2017, Das Gupta et al. 2018). Such risk of transmission is thought to result from maternal hyperglycemia (Kubo et al. 2014, Tam et al. 2017, Kawasaki et al. 2018); however, no direct evidence exists elucidating the exact role of maternal hyperglycemia in programming offspring metabolic health. Our fetomaternal hyperglycemia model, capable of inducing localized maternal and fetal hyperglycemia, addresses this knowledge gap. Using this model, where late gestation fetal pups were exposed to mild-moderate hyperglycemia $(<350 \mathrm{mg} / \mathrm{dL})$ (Aerts \& van Assche 1977, Blondeau et al. 2011, White et al. 2015), we first showed that hyperglycemic rodent offspring acutely developed a pancreatic islet phenotype similar to that of an infant of a diabetic mother (Helwig 1940, Cardell 1953) and identified DEGs that modulate pancreatic islet inflammation, cell viability and function. Along with transcriptome changes, metabolic testing during weaning showed that offspring exposed to hyperglycemia in utero developed glucose intolerance due to increased pancreatic islet susceptibility to cell death and decreased glucoseinduced insulin secretion. Finally, consistent with the altered fetal islet transcriptome and findings in weanlings, 


\begin{tabular}{|l|l|l|r|r|}
$\begin{array}{l}\text { Journal of } \\
\text { Endocrinology }\end{array}$ & J Casasnovas, Y Jo et al. & $\begin{array}{l}\text { Fetal hyperglycemia induces } \\
\text { islet hypofunction }\end{array}$ & $\mathbf{2 4 0 : 2}$ & $\mathbf{3 1 8}$ \\
\hline
\end{tabular}
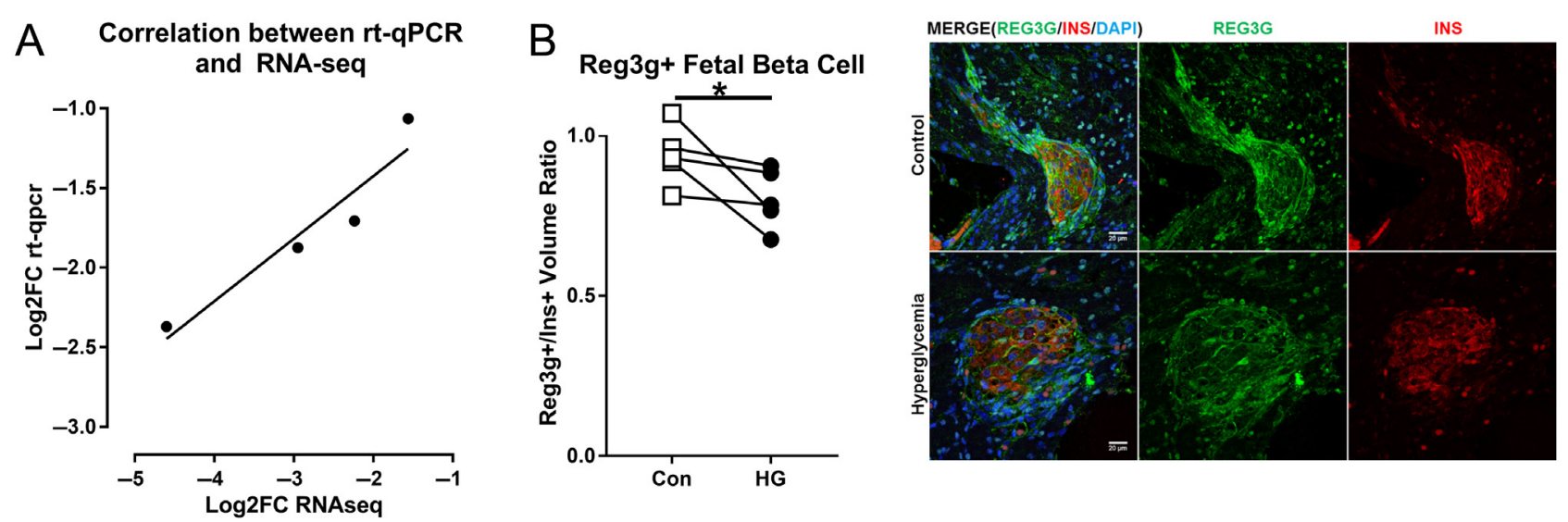

\section{Figure 3}

Validation of RNA-seq results. (A) Graph correlating four downregulated differentially expressed genes (from left-right: Reg3g: $n=4$ fetal islet samples/ group, Reg3b: $n=4$ fetal islet samples/group, Mmp7: $n=3$ fetal islet samples/group, Gabrp: $n=5$ fetal islet samples/group) (one technical replicate from RNA-seq experiment was included in Reg3g, Reg3b and Gabrp). (B) Graph showing consistent decrease in area positive for REG3G in pancreatic beta cell area (INS+) (*paired $t$-test $P<0.05$, each symbol represents an average data point obtained from three to five islets per sections, total of two sections per fetus, $n=5 \mathrm{GD} 22$ fetuses/group from five mothers). Internal pairs were connected with solid line. Image panel on right showing representative immunofluorescence images obtained from pancreatic tissue of Con and HG pups' pancreatic sections on the same slide.

adult offspring exposed to late gestation hyperglycemia showed decreased beta cell mass and insulin secretory function.

There are a number of investigations that performed targeted molecular studies on offspring exposed to different diabetic pregnancy models. These studies identified that pancreatic islets collected from young offspring exposed to diabetic milieu in utero had altered IGF2/insulin receptor signaling (Ding et al. 2012, Bringhenti et al. 2016), altered glucose metabolism (Han et al. 2007, Cerf et al. 2009), and/or increased oxidative stress/inflammation (Wang et al. 2014, Yokomizo et al. 2014). While the hyperglycemic islet transcriptome predicted heightened inflammation, the DEGs and pathway analysis did not show changes in genes related to IGF2/insulin receptor signaling or enzymes regulating pancreatic islet glucose metabolism. This discrepancy could be due to multiple reasons, the first being the difference in our model and timepoint examination of offspring islets. Our model addressed the direct effects of hyperglycemia during late gestation, as opposed to other models that exposed the fetus to more complex metabolic perturbations throughout pregnancy and subsequently addressing the molecular pathways altered in offspring later in life. Additionally, all of the aforementioned studies, except for the study by Ding et al. (2012), examined the effects of maternal diabetes/ overnutrition in young adult offspring.

Overall, the transcriptome analysis and literature review on individual DEGs predicted three major processes that regulate offspring pancreatic islet health: increased inflammation, susceptibility to cell death and decreased pancreatic islet insulin secretion. Particularly, the upregulated genes were heavily enriched in inflammatory pathways and an activated cell death process. Since there was absence of systemic inflammation, we reasoned that increased inflammation is not the primary mechanism inducing offspring pancreatic islet dysfunction. Rather, we hypothesized that the observed increased in inflammatory-related transcriptome in offspring exposed to late gestation hyperglycemia is stimulated by the increased in pancreatic islet susceptibility to cell death. The downregulated genes are closely related to pancreatic islet cells (Supplementary Table 3) and appear to have more diverse biological roles ranging from modulating pancreatic islet development, inflammatory response, anti-apoptotic effects and normal/compensatory beta cell insulin secretion (Table 2). The cystic fibrosis transmembrane conductance regulator (Cftr) has been increasingly recognized for its importance in cystic fibrosis-related diabetes (CFRD): the pathogenesis of which involves altered early life pancreatic islet morphogenesis (Rotti et al. 2018) and beta cell loss and intra-islet inflammation (Hart et al. 2018). Connective tissue growth factor (Ctgf) and fibroblast growth factor receptor 3 (Fgfr3) are another two downregulated genes that can affect early postnatal pancreatic islet development both morphologically and functionally. Both these genes are expressed only in late embryonic beta cell development and emerging islets (Arnaud-Dabernat et al. 2007, Crawford et al. 2009). Particularly, Ctgf inactivation during 
A

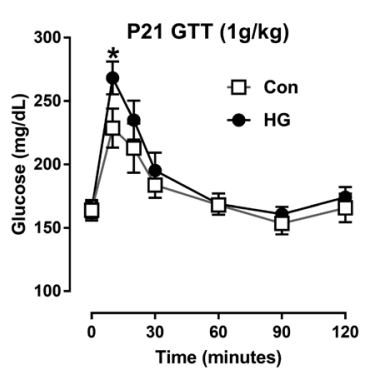

C

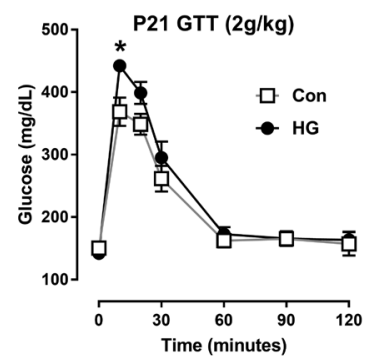

E ${ }^{1000} \quad$ Cell Viability Assay

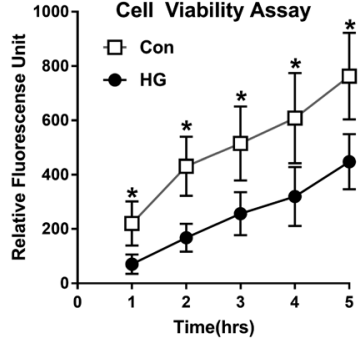

G

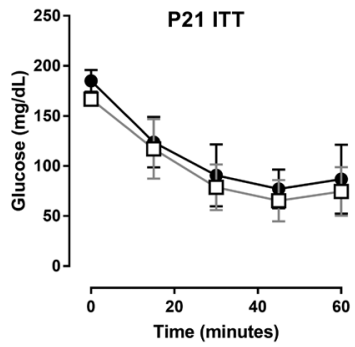

B
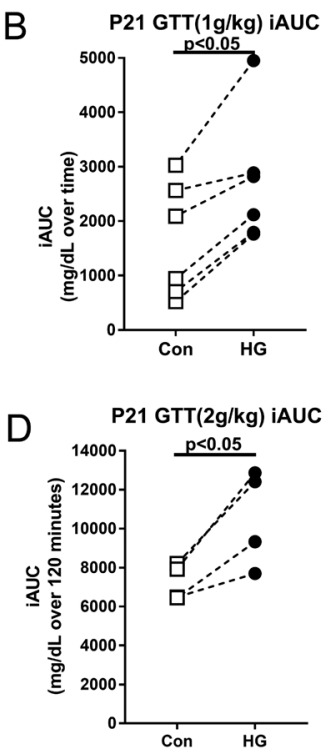

$\mathrm{F}$

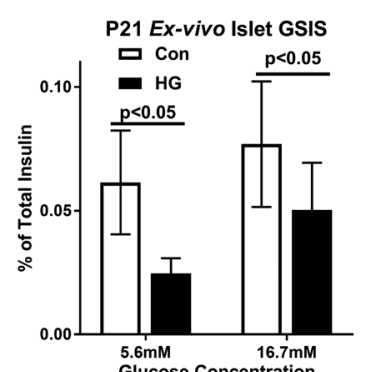

Figure 4

HG weanlings developed glucose intolerance and pancreatic islet insulin secretory defect. (A) $1 \mathrm{~g} / \mathrm{kg}$ intraperitoneal glucose tolerance testing showing increased blood glucose level at ten timepoint and (B) higher incremental glucose area under the curve (iAUC) (* $P<0.05, n=7-10$ male weanlings from six mothers, internal pairs were connected with dashed lines). (C) $2 \mathrm{~g} / \mathrm{kg}$ intraperitoneal glucose tolerance testing yielded the same result where HG pups continued to have a higher glucose level at 10 min and (D) a higher incremental glucose AUC ( ${ }^{*} P<0.05, n=7-9$ male weanlings/group from four mothers, internal pairs were connected with dashed lines). (E) Alamar blue cell viability assay showing the cell viability of HG islets was decreased ( ${ }^{*} P<0.05,7-8$ islets per replicate, $n=4$ pups/ group from four mothers). (F) Ex vivo static GSIS showing decreased HG islets insulin secretion at $5.6 \mathrm{mM}$ glucose and $16.7 \mathrm{mM}$ glucose phase ( $* P<0.05,20-25$ islets/group collected from $n=5$ weanlings/group from five mothers). (G) Insulin tolerance testing of weanling males ( $n=4-6 \mathrm{HG}$ male/group from three mothers).

embryogenesis caused decreased insulin-positive cells (Crawford et al. 2009), while Ctgf haploinsufficiency mice had decreased beta cell proliferation during pregnancy (Pasek et al. 2017).

Interestingly, the two most downregulated genes, $\operatorname{Reg} 3 g$ and $\operatorname{Reg} 3 b$, were from the common regenerating islet-derived protein (REG protein) family. Based on DNA sequence and protein structure similarities, these two REG proteins are classified under type 3 REG (Abe et al. 2000), which is expressed in pancreatic tissue (Parikh et al. 2012) and suggested to pattern embryonic endocrine cells (Hamblet et al. 2008). REG gene expression levels correlate with insulin secretory function (Madrid et al. 2013) and treatment using INGAP, one of the subtypes of REG protein, enhances neonatal islet insulin secretion (Barbosa et al. 2006, Madrid et al. 2009). More importantly, REG protein expression is upregulated in diabetic human islets (Marselli et al. 2010, Planas et al. 2010), with animal models supporting their role as a compensatory factor during islet stress (Siddique \& Awan 2016, Xia et al. 2016). In regard to the downstream signaling pathway, ex vivo (keratinocytes) (Barbosa et al. 2008, Lai et al. 2012, Wu et al. 2016) and in vivo (Xia et al. 2016) studies have indicated that REG3G/REG3A protein binds to EXTL3, which subsequently activates AKT and/or STAT3 downstream signaling. While we have not performed further protein evaluation in our model, IPA indicated the involvement of STAT3 pathway $(-\log P$ value $=3.28)$ with STAT3 predicted as an inhibited upstream regulator with the lowest $Z$ score (Exp FC: $-1.214, Z$-score $=-3.65,-\log P$ value $=16.8$, $-\log$ adjusted $P$ value $=14.0$ ). Considering these reported roles of REG protein, our findings indicate that decreased $R e g 3 g$ and/or Reg3b in pups exposed to hyperglycemia in utero would negatively impact postnatal pancreatic islet formation and/or functional maturation leading to decreased offspring islet cell viability and function. Therefore, future studies are warranted to determine the implication of decreased Type 3 REG during early postnatal pancreatic islet development (Lai et al. 2012, Wu et al. 2016).

Both pancreatic beta cell mass and glucose responsiveness increase most significantly after weaning (Jacovetti et al. 2015, Bonner-Weir et al. 2016); changes in islet susceptibility to cell death and decrease in function could determine pancreatic islet mass and function in adulthood. Therefore, it is not surprising that the findings describing increased susceptibility to cell death and 
A
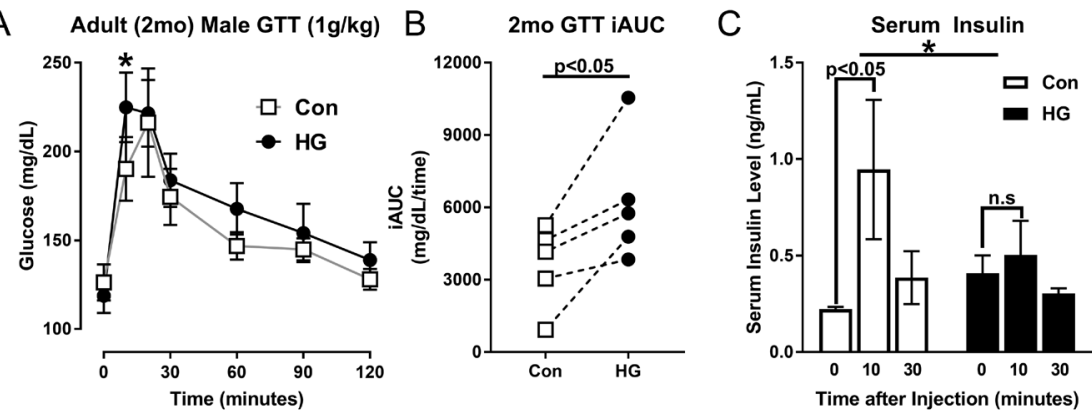

\section{Figure 5}

(A) $1 \mathrm{~g} / \mathrm{kg}$ intraperitoneal glucose tolerance testing on 2-month-old adult male offspring showing higher blood glucose level at 10 min timepoint and (B) higher incremental glucose iAUC $(n=6-7$ male/group, five mothers). (C) Serum insulin at 0 , 10 and 30 min timepoints during GTT showing decreased 10 min serum insulin level in HG male adult ( $n=4$ males/group, four mothers, $* P<0.05$ when statistic was performed on fold change of insulin from baseline). (D) Graph showing consistent trend $(P=0.06)$ of decrease in beta cell area across adult pancreatic sections, with a (E) decreased in pancreatic weight and ultimately decreased in (F) beta cell mass ( $n=4$ males/group from four mothers). (G) Offspring weight from birth until adulthood (birth $n=64-71$ pups from 14 mothers; $7 \mathrm{~d} / \mathrm{o} n=7-14$ pups from three mothers; $14 \mathrm{~d} / \mathrm{o} n=12-13$ pups from three mothers; $21 \mathrm{~d} / \mathrm{o} n=17-19$ males from six mothers; 2 months $n=6-7$ males from five mothers). (H) Fat to lean ratio of weanling ( $n=3-5$ males/group from three mothers) and 2-monthold adult showing no difference between Con and HG offspring ( $n=9-10$ males from seven mothers).

the insulin secretory defect during weaning negatively impacted HG offspring pancreatic beta cell mass and insulin secretory defect. This finding is consistent with both human epidemiological data (Tam et al. 2017) and an animal model mimicking diabetic pregnancy with mild-to-moderate maternal hyperglycemia $(<350 \mathrm{mg} / \mathrm{dL})$ (Aerts \& van Assche 1977, Blondeau et al. 2011, White et al. 2015). Most importantly, we showed that late gestation hyperglycemia, even for a short duration $(<10 \%$ of pregnancy), exhibited long-lasting negative impacts on offspring pancreatic islet function. These findings stress not only the critical role of maternal hyperglycemia, but also the importance of examining the metabolic outcome of offspring early in life for both human and animal studies.

\section{Conclusion}

In conclusion, late gestation hyperglycemia perturbs fetal pancreatic islet morphology and diminishes insulin secretory function in young offspring.
Transcriptome analysis indicated that GD22 islets exposed to in utero hyperglycemia displayed heightened inflammatory responses, increased susceptibility to cell death and decreased pancreatic islet insulin secretory function. This finding guided our study to identify pancreatic islet dysfunction in weanlings, which predisposed adult offspring to decreased beta cell mass and insulin secretion. Our transcriptome analysis provides a paradigm for elucidating the programming mechanism resulting from excessive glucose exposure. Future studies validating the targets in modulating postnatal pancreatic islet neogenesis and function are warranted.

\section{Supplementary data}

This is linked to the online version of the paper at https://doi.org/10.1530/ JOE-18-0493.

\section{Declaration of interest}

The authors declare that there is no conflict of interest that could be perceived as prejudicing the impartiality of the research reported. 


\section{Funding}

This project was funded by the Riley Children's Foundation Physician Scientists Scholar Award (K L K).

\section{Author contribution statement}

Conceived study: $K L K, J C, Y$ J. Designed and performed experiments: $K L K$, J C, Y J, XX. Data analysis: K L K, X R (RNA-seq), M E B (immunofluorescence and image analysis). Results interpretation: All authors. Manuscript preparation: J C, Y J, M E B, K L K. All authors reviewed and approved of the manuscript.

\section{Acknowledgements}

The authors thank Dr Carmella Evans-Molina, Dr Paul Rozance, Dr Laura Haneline, Dr Christina Santangelo (I3 Program) and Dr John Paul Spence (I3 Program) for reviewing the manuscript. They also thank Jun Wang and Jun Li from the Center of Medical Genomics at Indiana University School of Medicine for performing RNA sequencing.

\section{References}

Abe M, Nata K, Akiyama T, Shervani NJ, Kobayashi S, TomiokaKumagai T, Ito S, Takasawa S \& Okamoto H 2000 Identification of a novel Reg family gene, Reg IIIS, and mapping of all three types of Reg family gene in a 75 kilobase mouse genomic region. Gene 246 111-122. (https://doi.org/10.1016/S0378-1119(00)00059-7)

Aerts L \& van Assche FA 1977 Rat foetal endocrine pancreas in experimental diabetes. Journal of Endocrinology 73 339-346. (https:// doi.org/10.1677/joe.0.0730339)

Arnaud-Dabernat S, Kritzik M, Kayali AG, Zhang Y-Q, Liu G, Ungles C \& Sarvetnick N 2007 FGFR3 is a negative regulator of the expansion of pancreatic epithelial cells. Diabetes 56 96-106. (https://doi. org/10.2337/db05-1073)

Artner I, Blanchi B, Raum JC, Guo M, Kaneko T, Cordes S, Sieweke M \& Stein R 2007 MafB is required for islet beta cell maturation. PNAS 104 3853-3858. (https://doi.org/10.1073/pnas.0700013104)

Assouline-Thomas B, Ellis D, Petropavlovskaia M, Makhlin J, Ding J \& Rosenberg L 2015 Islet Neogenesis Associated Protein (INGAP) induces the differentiation of an adult human pancreatic ductal cell line into insulin-expressing cells through stepwise activation of key transcription factors for embryonic beta cell development. Differentiation 90 77-90. (https://doi.org/10.1016/j.diff.2015.10.008)

Barbosa H, Bordin S, Stoppiglia L, Silva K, Borelli M, Del Zotto H, Gagliardino J \& Boschero A 2006 Islet neogenesis associated protein (INGAP) modulates gene expression in cultured neonatal rat islets. Regulatory Peptides 136 78-84. (https://doi.org/10.1016/j. regpep.2006.04.015)

Barbosa HC, Bordin S, Anhê G, Persaud SJ, Bowe J, Borelli MI, Gagliardino JJ \& Boschero AC 2008 Islet neogenesis-associated protein signaling in neonatal pancreatic rat islets: involvement of the cholinergic pathway. Journal of Endocrinology 199 299-306. (https:// doi.org/10.1677/JOE-08-0309)

Blondeau B, Joly B, Perret C, Prince S, Bruneval P, Lelièvre-Pégorier M, Fassot C \& Duong Van Huyen J-P 2011 Exposure in utero to maternal diabetes leads to glucose intolerance and high blood pressure with no major effects on lipid metabolism. Diabetes and Metabolism 37 245-251. (https://doi.org/10.1016/j.diabet.2010.10.008)

Bonner-Weir S, Aguayo-Mazzucato C \& Weir GC 2016 Dynamic development of the pancreas from birth to adulthood. Upsala Journal of Medical Sciences 121 155-158. (https://doi.org/10.3109/03009734.2 016.1154906)

Bringhenti I, Ornellas F, Mandarim-de-Lacerda CA \& Aguila MB 2016 The insulin-signaling pathway of the pancreatic islet is impaired in adult mice offspring of mothers fed a high-fat diet. Nutrition 32 1138-1143. (https://doi.org/10.1016/j.nut.2016.03.001)

Cardell BS 1953 The infants of diabetic mothers; a morphological study. BJOG: An International Journal of Obstetrics and Gynaecology 60 834-853. (https://doi.org/10.1111/j.1471-0528.1953.tb07282.x)

Cerf ME, Muller CJ, Du Toit DF, Louw J \& Wolfe-Coote SA 2006 Hyperglycaemia and reduced glucokinase expression in weanling offspring from dams maintained on a high-fat diet. British Journal of Nutrition 95 391-396. (https://doi.org/10.1079/BJN20051632)

Cerf ME, Chapman CS, Muller CJ \& Louw J 2009 Gestational highfat programming impairs insulin release and reduces Pdx-1 and glucokinase immunoreactivity in neonatal Wistar rats. Metabolism $\mathbf{5 8}$ 1787-1792. (https://doi.org/10.1016/j.metabol.2009.06.007)

Clausen TD, Mathiesen ER, Hansen T, Pedersen O, Jensen DM, Lauenborg J \& Damm P 2008 High prevalence of type 2 diabetes and pre-diabetes in adult offspring of women with gestational diabetes mellitus or type 1 diabetes: the role of intrauterine hyperglycemia. Diabetes Care 31 340-346. (https://doi.org/10.2337/dc07-1596)

Crawford LA, Guney MA, Oh YA, Andrea DeYoung RA, Valenzuela DM, Murphy AJ, Yancopoulos GD, Lyons KM, Brigstock DR, Economides A, et al. 2009 Connective tissue growth factor (CTGF) inactivation leads to defects in islet cell lineage allocation and beta-cell proliferation during embryogenesis. Molecular Endocrinology 23 324-336. (https:// doi.org/10.1210/me.2008-0045)

Das Gupta R, Gupta S, Das A, Biswas T, Haider MR \& Sarker M 2018 Ethnic predisposition of diabetes mellitus in the patients with previous history of gestational diabetes mellitus: a review. Expert Review of Endocrinology and Metabolism 13 149-158. (https://doi.org/1 $0.1080 / 17446651.2018 .1471354)$

DeSisto CL, Kim SY \& Sharma AJ 2014 Prevalence estimates of gestational diabetes mellitus in the United States, pregnancy risk assessment monitoring system (PRAMS), 2007-2010. Preventing Chronic Disease 11 E104. (https://doi.org/10.5888/pcd11.130415)

Ding G-L, Wang F-F, Shu J, Tian S, Jiang Y, Zhang D, Wang N, Luo Q, Zhang Y, Jin F, et al. 2012 Transgenerational glucose intolerance with Igf2/H19 epigenetic alterations in mouse islet induced by intrauterine hyperglycemia. Diabetes 61 1133-1142. (https://doi.org/10.2337/ db11-1314)

Dobin A, Davis CA, Schlesinger F, Drenkow J, Zaleski C, Jha S, Batut P, Chaisson M \& Gingeras TR 2013 STAR: ultrafast universal RNAseq aligner. Bioinformatics 29 15-21. (https://doi.org/10.1093/ bioinformatics/bts635)

Fraser A \& Lawlor DA 2014 Long-term health outcomes in offspring born to women with diabetes in pregnancy. Current Diabetes Reports 14 489. (https://doi.org/10.1007/s11892-014-0489-x)

Frost MS, Zehri AH, Limesand SW, Hay WW Jr \& Rozance PJ 2012 Differential effects of chronic pulsatile versus chronic constant maternal hyperglycemia on fetal pancreatic $\beta$-cells. Journal of Pregnancy 2012 812094. (https://doi.org/10.1155/2012/812094)

Gagliardino JJ, Del Zotto H, Massa L, Flores LE \& Borelli MI 2003 Pancreatic duodenal homeobox-1 and islet neogenesis-associated protein: a possible combined marker of activateable pancreatic cell precursors. Journal of Endocrinology 177 249-259.

Gain KR, Malthus R \& Watts C 1981 Glucose homeostasis during the perinatal period in normal rats and rats with a glycogen storage disorder. Journal of Clinical Investigation 67 1569-1573. (https://doi. org/10.1172/JCI110188)

Gautier J-F, Wilson C, Weyer C, Mott D, Knowler WC, Cavaghan M, Polonsky KS, Bogardus C \& Pratley RE 2001 Low acute insulin secretory responses in adult offspring of people with early onset type 2 diabetes. Diabetes 50 1828-1833. (https://doi.org/10.2337/ diabetes.50.8.1828) 
Gordon EE, Reinking BE, Hu S, Yao J, Kua KL, Younes AK, Wang C, Segar JL \& Norris AW 2015 Maternal hyperglycemia directly and rapidly induces cardiac septal overgrowth in fetal rats. Journal of Diabetes Research 2015 1-11. (https://doi.org/10.1155/2015/479565)

Green AS, Chen X, Macko AR, Anderson MJ, Kelly AC, Hart NJ, Lynch RM \& Limesand SW 2012 Chronic pulsatile hyperglycemia reduces insulin secretion and increases accumulation of reactive oxygen species in fetal sheep islets. Journal of Endocrinology $\mathbf{2 1 2}$ 327-342. (https://doi.org/10.1530/JOE-11-0300)

Hamblet NS, Shi W, Vinik AI \& Taylor-Fishwick DA 2008 The Reg family member INGAP is a marker of endocrine patterning in the embryonic pancreas. Pancreas 36 1-9. (https://doi.org/10.1097/ MPA.0b013r318148c8e6)

Han J, Xu J, Long YS, Epstein PN \& Liu YQ 2007 Rat maternal diabetes impairs pancreatic beta-cell function in the offspring. American Journal of Physiology: Endocrinology and Metabolism 293 E228-E236. (https://doi.org/10.1152/ajpendo.00479.2006)

Hart NJ, Aramandla R, Poffenberger G, Fayolle C, Thames AH, Bautista A, Spigelman AF, Babon JAB, DeNicola ME, Dadi PK, et al. 2018 Cystic fibrosis-related diabetes is caused by islet loss and inflammation. JCI Insight 3 98240. (https://doi.org/10.1172/jci.insight.98240)

Helwig EB 1940 Hypertrophy and hyperplasia of islands of langerhans in infants born of diabetic mothers. Archives of Internal Medicine $\mathbf{6 5} 221$. (https://doi.org/10.1001/archinte.1940.00190080003001)

Hunt KJ \& Schuller KL 2007 The increasing prevalence of diabetes in pregnancy. Obstetrics and Gynecology Clinics of North America $\mathbf{3 4}$ 173-199. (https://doi.org/10.1016/i.ogc.2007.03.002)

Jacovetti C, Matkovich SJ, Rodriguez-Trejo A, Guay C \& Regazzi R 2015 Postnatal $\beta$-cell maturation is associated with islet-specific microRNA changes induced by nutrient shifts at weaning. Nature Communications 6 8084. (https://doi.org/10.1038/ncomms9084)

Jacovetti C, Rodriguez-Trejo A, Guay C, Sobel J, Gattesco S, Petrenko V, Saini C, Dibner C \& Regazzi R 2017 MicroRNAs modulate core-clock gene expression in pancreatic islets during early postnatal life in rats. Diabetologia 60 2011-2020. (https://doi.org/10.1007/s00125-0174348-6)

Kaya-Dagistanli F \& Ozturk M 2013 The role of clusterin on pancreatic beta cell regeneration after exendin- 4 treatment in neonatal streptozotocin administrated rats. Acta Histochemica 115 577-586. (https://doi.org/10.1016/j.acthis.2012.12.007)

Kawasaki M, Arata N, Miyazaki C, Mori R, Kikuchi T, Ogawa Y \& Ota E 2018 Obesity and abnormal glucose tolerance in offspring of diabetic mothers: a systematic review and meta-analysis. PLOS ONE 13 e0190676. (https://doi.org/10.1371/journal.pone.0190676)

Koivula FNM, McClenaghan NH, Harper AGS \& Kelly C 2016 Isletintrinsic effects of CFTR mutation. Diabetologia 59 1350-1355. (https://doi.org/10.1007/s00125-016-3936-1)

Komatsu M, Schermerhorn T, Aizawa T \& Sharp GW 1995 Glucose stimulation of insulin release in the absence of extracellular Ca2 and in the absence of any increase in intracellular $\mathrm{Ca} 2$ in rat pancreatic islets. PNAS 92 10728-10732. (https://doi.org/10.1073/ pnas.92.23.10728)

Kubo A, Ferrara A, Windham GC, Greenspan LC, Deardorff J, Hiatt RA, Quesenberry CP Jr, Laurent C, Mirabedi AS \& Kushi LH 2014 Maternal hyperglycemia during pregnancy predicts adiposity of the offspring. Diabetes Care 37 2996-3002. (https://doi.org/10.2337/dc14-1438)

Lai Y, Li D, Li C, Muehleisen B, Radek KA, Park HJ, Jiang Z, Li Z, Lei H, Quan Y, et al. 2012 The antimicrobial protein REG3A regulates keratinocyte proliferation and differentiation after skin injury. Immunity 37 74-84. (https://doi.org/10.1016/j.immuni.2012.04.010)

Liao Y, Smyth GK \& Shi W 2014 featureCounts: an efficient general purpose program for assigning sequence reads to genomic features. Bioinformatics 30 923-930. (https://doi.org/10.1093/bioinformatics/ btt656)

Madrid V, Del Zotto H, Maiztegui B, Raschia MA, Alzugaray ME, Boschero AC, Barbosa HC, Flores LE, Borelli MI \& Gagliardino JJ 2009
Islet neogenesis-associated protein pentadecapeptide (INGAP-PP): mechanisms involved in its effect upon beta-cell mass and function. Regulatory Peptides 157 25-31. (https://doi.org/10.1016/j. regpep.2009.05.011)

Madrid V, Borelli MI, Maiztegui B, Flores LE, Gagliardino JJ \& Zotto HD 2013 Islet neogenesis-associated protein (INGAP)-positive cell mass, $\beta$-cell mass, and insulin secretion: their relationship during the fetal and neonatal periods. Pancreas 42 422-428. (https://doi.org/10.1097/ MPA.0b013e318264c7bd)

Marselli L, Thorne J, Dahiya S, Sgroi DC, Sharma A, Bonner-Weir S, Marchetti P \& Weir GC 2010 Gene expression profiles of Beta-cell enriched tissue obtained by laser capture microdissection from subjects with type 2 diabetes. PLOS ONE 5 e11499. (https://doi. org/10.1371/journal.pone.0011499)

Martin B \& Sacks DA 2018 The global burden of hyperglycemia in pregnancy - trends from studies in the last decade. Diabetes Research and Clinical Practice 145 17-19. (https://doi.org/10.1016/j. diabres.2018.04.003)

McCarthy DJ, Chen Y \& Smyth GK 2012 Differential expression analysis of multifactor RNA-Seq experiments with respect to biological variation. Nucleic Acids Research 40 4288-4297. (https://doi. org/10.1093/nar/gks042)

Mehta ZB, Fine N, Pullen TJ, Cane MC, Hu M, Chabosseau P, Meur G, Velayos-Baeza A, Monaco AP, Marselli L, et al. 2016 Changes in the expression of the type 2 diabetes-associated gene VPS13C in the $\beta$-cell are associated with glucose intolerance in humans and mice. American Journal of Physiology: Endocrinology and Metabolism 311 E488-E507. (https://doi.org/10.1152/ajpendo.00074.2016)

Mi H, Huang X, Muruganujan A, Tang H, Mills C, Kang D \& Thomas PD 2017 PANTHER version 11: expanded annotation data from Gene Ontology and Reactome pathways, and data analysis tool enhancements. Nucleic Acids Research 45 D183-D189. (https://doi. org/10.1093/nar/gkw1138)

Muthyala S, Safley S, Gordan K, Barber G, Weber C \& Sambanis A 2017 The effect of hypoxia on free and encapsulated adult porcine islets-an in vitro study. Xenotransplantation 24 [epub]. (https://doi. org/10.1111/xen.12275)

Nishihama K, Yasuma T, Yano Y, D'Alessandro-Gabazza CN, Toda M, Hinneh JA, Baffour Tonto P, Takeshita A, Totoki T, MifujiMoroka R, et al. 2018 Anti-apoptotic activity of human matrix metalloproteinase-2 attenuates diabetes mellitus. Metabolism: Clinical and Experimental 82 88-99. (https://doi.org/10.1016/j. metabol.2018.01.016)

Parikh A, Stephan A-F \& Tzanakakis ES 2012 Regenerating proteins and their expression, regulation and signaling. Biomolecular Concepts 3 57-70. (https://doi.org/10.1515/bmc.2011.055)

Pasek RC, Dunn JC, Elsakr JM, Aramandla M, Matta AR \& Gannon M 2017 Vascular-derived connective tissue growth factor (Ctgf) is critical for pregnancy-induced $\beta$ cell hyperplasia in adult mice. Islets 9 150-158. (https://doi.org/10.1080/19382014.2017.1356963)

Perez SE, Cano DA, Dao-Pick T, Rougier J-P, Werb Z \& Hebrok M 2005 Matrix metalloproteinases 2 and 9 are dispensable for pancreatic islet formation and function in vivo. Diabetes 54 694-701. (https://doi. org/10.2337/diabetes.54.3.694)

Petropavlovskaia M, Makhlin J, Sampalis J \& Rosenberg L 2006 Development of an in vitro pancreatic tissue model to study regulation of islet neogenesis associated protein expression. Journal of Endocrinology 191 65-81. (https://doi.org/10.1677/joe.1.06800)

Planas R, Carrillo J, Sanchez A, de Villa MCR, Nuñez F, Verdaguer J, James RFL, Pujol-Borrell R \& Vives-Pi M 2010 Gene expression profiles for the human pancreas and purified islets in type 1 diabetes: new findings at clinical onset and in long-standing diabetes. Clinical and Experimental Immunology 159 23-44. (https://doi.org/10.1111/j.13652249.2009.04053.x)

Prud'homme GJ, Glinka Y, Udovyk O, Hasilo C, Paraskevas S \& Wang Q 2014 GABA protects pancreatic beta cells against apoptosis by https://joe.bioscientifica.com

https://doi.org/10.1530/JOE-18-0493 (c) 2019 Society for Endocrinology Published by Bioscientifica Ltd. Printed in Great Britain 
increasing SIRT1 expression and activity. Biochemical and Biophysical Research Communications 452 649-654. (https://doi.org/10.1016/j. bbrc.2014.08.135)

Raghavan S, Zhang W, Yang IV, Lange LA, Lange EM, Fingerlin TE \& Dabelea D 2017 Association between gestational diabetes mellitus exposure and childhood adiposity is not substantially explained by offspring genetic risk of obesity. Diabetic Medicine 34 1696-1700. (https://doi.org/10.1111/dme.13529)

Ratner RE, Christophi CA, Metzger BE, Dabelea D, Bennett PH, Pi-Sunyer X, Fowler S \& Kahn SE 2008 Prevention of diabetes in women with a history of gestational diabetes: effects of metformin and lifestyle interventions. Journal of Clinical Endocrinology and Metabolism 93 4774-4779. (https://doi.org/10.1210/jc.2008-0772)

Riley KG, Pasek RC, Maulis MF, Dunn JC, Bolus WR, Kendall PL, Hasty AH \& Gannon M 2015 Macrophages are essential for CTGF-mediated adult $\beta$-cell proliferation after injury. Molecular Metabolism 4 584-591. (https://doi.org/10.1016/j.molmet.2015.05.002)

Robinson MD, McCarthy DJ \& Smyth GK 2010 edgeR: a Bioconductor package for differential expression analysis of digital gene expression data. Bioinformatics 26 139-140. (https://doi.org/10.1093/ bioinformatics/btp616)

Roest HP, Baarends WM, de Wit J, van Klaveren JW, Wassenaar E, Hoogerbrugge JW, van Cappellen WA, Hoeijmakers JHJ \& Grootegoed JA 2004 The ubiquitin-conjugating DNA repair enzyme HR6A is a maternal factor essential for early embryonic development in mice. Molecular and Cellular Biology 24 5485-5495. (https://doi. org/10.1128/MCB.24.12.5485-5495.2004)

Rotti PG, Xie W, Poudel A, Yi Y, Sun X, Tyler SR, Uc A, Norris AW, Hara M, Engelhardt JF, et al. 2018 Pancreatic and islet remodeling in cystic fibrosis transmembrane conductance regulator (CFTR) knockout ferrets. American Journal of Pathology 188 876-890. (https:// doi.org/10.1016/j.ajpath.2017.12.015)

Sauder KA, Hockett CW, Ringham BM, Glueck DH \& Dabelea D 2017 Fetal overnutrition and offspring insulin resistance and $\beta$-cell function: the Exploring Perinatal Outcomes among Children (EPOCH) study. Diabetic Medicine 34 1392-1399. (https://doi. org/10.1111/dme.13417)

Schindelin J, Arganda-Carreras I, Frise E, Kaynig V, Longair M, Pietzsch T, Preibisch S, Rueden C, Saalfeld S, Schmid B, et al. 2012 Fiji: an open-source platform for biological-image analysis. Nature Methods 9 676-682. (https://doi.org/10.1038/nmeth.2019)

Siddique T \& Awan FR 2016 Effects of Reg3 delta bioactive peptide on blood glucose levels and pancreatic gene expression in an alloxaninduced mouse model of diabetes. Canadian Journal of Diabetes $\mathbf{4 0}$ 198-203. (https://doi.org/10.1016/j.jcjd.2015.09.096)

Stull ND, Breite A, McCarthy R, Tersey SA \& Mirmira RG 2012 Mouse islet of Langerhans isolation using a combination of purified collagenase and neutral protease. Journal of Visualized Experiments 4137. (https:// doi.org/10.3791/4137)

Supek F, Bošnjak M, Škunca N \& Šmuc T 2011 REVIGO summarizes and visualizes long lists of gene ontology terms. PLoS ONE 6 e21800. (https://doi.org/10.1371/journal.pone.0021800)

Tam WH, Ma RCW, Ozaki R, Li AM, Chan MHM, Yuen LY, Lao TTH, Yang X, Ho CS, Tutino GE, et al. 2017 In utero exposure to maternal hyperglycemia increases childhood cardiometabolic risk in offspring. Diabetes Care 40 679-686. (https://doi.org/10.2337/dc16-2397)

van der Meulen T \& Huising MO 2014 Maturation of stem cell-derived beta-cells guided by the expression of urocortin 3. Review of Diabetic Studies 11 115-132. (https://doi.org/10.1900/RDS.2014.11.115)

Vieleisis RA \& Oh W 1983 Effect of increased substrate availability on fatty acid synthesis in the growth retarded fetus. Metabolism $\mathbf{3 2}$ 90-94. (https://doi.org/10.1016/0026-0495(83)90162-2)

Wang J, Ma H, Tong C, Zhang H, Lawlis GB, Li Y, Zang M, Ren J, Nijland MJ, Ford SP, et al. 2010 Overnutrition and maternal obesity in sheep pregnancy alter the JNK-IRS-1 signaling cascades and cardiac function in the fetal heart. FASEB Journal 24 2066-2076. (https://doi. org/10.1096/fj.09-142315)

Wang H, Xue Y, Wang B, Zhao J, Yan X, Huang Y, Du M \& Zhu M-J 2014 Maternal obesity exacerbates insulitis and type 1 diabetes in nonobese diabetic mice. Reproduction 148 73-79. (https://doi.org/10.1530/ REP-13-0614)

White V, Jawerbaum A, Mazzucco MB, Gauster M, Desoye G \& Hiden U 2015 Diabetes-associated changes in the fetal insulin/insulin-like growth factor system are organ specific in rats. Pediatric Research $\mathbf{7 7}$ 48-55. (https://doi.org/10.1038/pr.2014.139)

Wu Y, Quan Y, Liu Y, Liu K, Li H, Jiang Z, Zhang T, Lei H, Radek KA, Li D, et al. 2016 Hyperglycaemia inhibits REG3A expression to exacerbate TLR3-mediated skin inflammation in diabetes. Nature Communications 7 13393. (https://doi.org/10.1038/ncomms13393)

Xia F, Cao H, Du J, Liu X, Liu Y \& Xiang M 2016 Reg3g overexpression promotes $\beta$ cell regeneration and induces immune tolerance in nonobese-diabetic mouse model. Journal of Leukocyte Biology 99 1131-1140. (https://doi.org/10.1189/jlb.3A0815-371RRR)

Xiang L, Naik JS, Abram SR \& Hester RL 2007 Chronic hyperglycemia impairs functional vasodilation via increasing thromboxane-receptormediated vasoconstriction. American Journal of Physiology: Heart and Circulatory Physiology 292 H231-H236. (https://doi.org/10.1152/ ajpheart.00623.2006)

Yao J, Wang C, Walsh SA, Hu S, Sawatzke AB, Dang D, Segar JL, Ponto LLB, Sunderland JJ \& Norris AW 2010 Localized fetomaternal hyperglycemia: spatial and kinetic definition by positron emission tomography. PLoS ONE 5 e12027. (https://doi.org/10.1371/journal.pone.0012027)

Yaochite JNU, Caliari-Oliveira C, Davanso MR, Carlos D, Malmegrim KCR, Cardoso CR de B, Ramalho LNZ, Palma PVB, da Silva JS, Cunha FQ, et al. 2013 Dynamic changes of the Th17/Tc17 and regulatory $\mathrm{T}$ cell populations interfere in the experimental autoimmune diabetes pathogenesis. Immunobiology 218 338-352. (https://doi.org/10.1016/j. imbio.2012.05.010)

Yokomizo H, Inoguchi T, Sonoda N, Sakaki Y, Maeda Y, Inoue T, Hirata E, Takei R, Ikeda N, Fujii M, et al. 2014 Maternal high-fat diet induces insulin resistance and deterioration of pancreatic $\beta$-cell function in adult offspring with sex differences in mice. American Journal of Physiology: Endocrinology and Metabolism 306 E1163-E1175. (https:// doi.org/10.1152/ajpendo.00688.2013)

Zambrano E, Sosa-Larios T, Calzada L, Ibáñez CA, Mendoza-Rodríguez CA, Morales A \& Morimoto S 2016 Decreased basal insulin secretion from pancreatic islets of pups in a rat model of maternal obesity. Journal of Endocrinology 231 49-57. (https://doi.org/10.1530/JOE-16-0321)

Received in final form 12 November 2018

Accepted 30 November 2018

Accepted Preprint published online 3 December 2018 https://joe.bioscientifica.com https://doi.org/10.1530/JOE-18-0493
(C) 2019 Society for Endocrinology Published by Bioscientifica Ltd.
Printed in Great Britain 